\title{
A Interpretação de ConferênCias: Interfaces com a Tradução Escrita e ImplicaÇões para a Formação de INTÉRPRETES E TraduTORES*
}

\author{
(Conference Interpreting Interfaces with Written Translation and \\ Implications for Interpreter and Translator Training)
}

\author{
Reynaldo PAGURA \\ (PUC-SP, Associação Alumni-SP e ISAT-RJ)
}

RESUMO: O presente trabalho faz uma breve retrospectiva da interpretação de conferências e apresenta semelhanças e diferenças entre o processo de tradução (escrita) e o de interpretação (oral). Tomando como base teórica a Teoria Interpretativa da Tradução, desenvolvida na Escola Superior de Intérpretes e Tradutores (ESIT) da Universidade Paris III (Sorbonne Nouvelle), o trabalho mostra como, apesar de semelhanças teóricas, os dois processos são operacionalizados de maneiras bastante diferentes. A seguir, discute algumas implicações para a formação de tradutores e de intérpretes resultantes da operacionalização dos dois processos.

PALAVRAS-CHAVE: Tradução; Interpretação; Teoria Interpretativa da Tradução; Formação de Tradutores e de Intérpretes.

ABSTRACT: This paper aims at presenting an overview of conference interpreting and shows similarities and differences between translating and interpreting. From the theoretical groundworks of the Interpretive Theory of Translation, developed at the ESIT (University of Paris III - Sorbonne Nouvelle), it shows that, despite theoretical similarities, the two processes have different operational constraints. The implications for translator and interpreter education resulting from these operational differences are then discussed.

KEY-WORDS: Translating; Interpreting; Interpretive Theory of Translation; Translator and Interpreter Education.

\footnotetext{
* Este trabalho é uma versão bastante modificada e ampliada de outros com tema semelhante publicado no periódico Claritas, da PUC-SP, e na BRAZ-TESOL Newsletter. A parte referente à história da interpretação foi apresentada em uma exposição durante mesa-redonda da qual o autor participou no II CIATI, realizado em 2001 na UNIBERO em São Paulo.
}

D.E.L.T.A., 19:EsPECIAL, 2003 (209-236) 


\section{Introdução}

"Os intérpretes existem desde a antigüidade, assim como os tradutores, com quem são freqüentemente confundidos; o tradutor trabalha com a palavra escrita, o intérprete com a palavra falada." ${ }^{1}$ Assim começa o livreto da União Européia (Commission of the European Communitoes, s/d) com informações para os candidatos a seus cursos de formação de intérpretes que atende às necessidades da instituição, o maior empregador de tradutores e intérpretes do mundo.

Embora a diferença seja bem clara para os profissionais dessas duas áreas, ainda é bastante comum ouvir referências ao "tradutor-intérprete", hábito talvez criado no Brasil com a edição da Lei 5692/71, também conhecida como a Lei da Reforma do Ensino, que incluía a formação do "tradutor-intérprete" como uma das inúmeras possibilidades dos cursos profissionalizantes a serem instituídos no ensino de segundo grau (atual Ensino Médio), o que era uma proposta bastante insensata, mas cuja análise não é objeto do presente artigo.

Embora não haja dúvidas de que a interpretação simultânea e a consecutiva envolvam um processo de tradução, no sentido mais amplo do termo - a conversão de uma mensagem de um idioma para outro e de uma cultura para outra -, a maioria dos teóricos e dos praticantes das duas áreas reserva o uso dos termos mencionados acima para duas atividades diferentes, conforme as delimitações já mencionadas. Quais são as semelhanças entre os dois processos que poderiam ter gerado tal confusão? E quais são as diferenças que viriam justificar uma separação entre as duas atividades? Que implicações essas possíveis semelhanças e diferenças teriam para o processo de formação de tradutores e de intérpretes?

\section{Breve Explicação dos Termos Usados na Prática da Interpretação}

Como a terminologia utilizada na Interpretação não é de amplo domínio dentre aqueles que não se dedicam a essa atividade, parece interessante explicar aqui alguns dos termos comumente utilizados. Fala-se comumente

\footnotetext{
1 Todas os trechos de citações escritos originalmente em inglês ou francês foram traduzidas pelo autor deste artigo.
} 
em dois modos de interpretação: consecutiva e simultânea (cd.: AIIC, s/d; Child 1992; Jones 1998; Mikkelson 2000; Seleskovitch 1978), aos quais o autor deste artigo acrescenta um terceiro - intermitente - que tem características diferentes dos outros dois, como se verá a seguir.

A modalidade consecutiva é aquela em que o intérprete escuta um longo trecho de discurso, toma notas e, após a conclusão de um trecho significativo ou do discurso inteiro, assume a palavra e repete todo o discurso na língua-alvo, normalmente a sua língua materna. A época áurea da interpretação consecutiva foi o período compreendido entre a Primeira e a Segunda Guerra Mundial, em que predominavam o francês e o inglês como línguas diplomáticas e de comunicação internacional e o grande fórum de debates internacionais era a Liga das Nações, com sede em Genebra, na Suíça. (cf.: Seleskovitch 1978: 3) Embora não seja mais comumente utilizada em grandes eventos internacionais, ainda é bastante usada em pequenos grupos, principalmente quando o evento envolve apenas dois idiomas. É importante ressaltar também que a consecutiva tem papel preponderante no treinamento de intérpretes simultâneos, uma vez que nesse modo se desenvolvem as técnicas que serão fundamentais para o desempenho da simultânea, tais como a capacidade de compreensão e análise do discurso de partida.

A modalidade simultânea é a mais amplamente utilizada hoje em dia, embora só tenha se firmado no pós-guerra, com as necessidades surgidas no Julgamento de Nuremberg, em que se utilizaram quatro idiomas (inglês, francês, russo e alemão) e, quase que imediatamente a seguir, com a criação da Organização das Nações Unidas, onde se utilizam seis idiomas oficiais (inglês, francês, espanhol, russo, chinês e árabe). Nessa modalidade, os intérpretes - sempre em duplas - trabalham isolados numa cabine com vidro, de forma a permitir a visão do orador e recebem o discurso por meio de fones de ouvido. Ao processar a mensagem, re-expressam-na na língua de chegada por meio de um microfone ligado a um sistema de som que leva sua fala até os ouvintes, por meio de fones de ouvido ou receptores semelhantes a rádios portáteis. Essa modalidade permite a tradução de uma mensagem em um número infinito de idiomas ao mesmo tempo, desde que o equipamento assim o permita. A interpretação simultânea não ocorre, de fato, simultaneamente à fala original, pois o intérprete tem necessidade de um espaço de tempo para processar a informação recebida 
e reorganizar sua forma de expressão. Esse breve espaço de tempo recebe o nome tradicional de "décalage", termo francês usado em todo o mundo. Uma outra forma de se realizar a interpretação simultânea é a chamada "interpretação cochichada" ou "chuchotage"- outro termo em francês usado por intérpretes de todo o mundo -, em que o intérprete se senta próximo a um ou dois ouvintes e interpreta simultaneamente a mensagem apresentada em outro idioma. Por ser essa a forma mais utilizada atualmente, não é nada incomum que as pessoas não familiarizadas com a terminologia profissional chamem de "simultânea" a qualquer tipo de interpretação que tenham presenciado.

A modalidade intermitente (ou "sentence-by-sentence", ou ainda "ping-pong") não é comumente estudada por pesquisadores da área, nem é utilizada por profissionais em eventos de caráter internacional. É vista mais freqüentemente em reuniões nas quais se pede a uma pessoa que fala as duas línguas, via de regra sem qualquer treino em interpretação, para que se coloque ao lado de um palestrante estrangeiro e traduza o que ele está dizendo. O palestrante fala uma ou duas frases curtas e faz uma pausa para que as suas sentenças sejam traduzidas para o idioma da platéia. Esse processo centra-se basicamente na tradução das palavras ditas, sem levar em conta diversos outros fatores importantes no processo interpretativo, seja pela própria natureza da situação ou, muito comumente, pela falta total de treino da pessoa colocada na posição de "intérprete". É comum algumas pessoas confundirem essa modalidade de interpretação com o que os profissionais chamam de consecutiva, já mencionada acima.

Podemos ainda nos referir a diversos tipos de interpretação, em função de onde e quando ocorram (cf.: Childs 1992; Mikkelson, 2000). Os três modos mencionados acima podem ocorrer em todas as situações a seguir. Falamos, comumente, em interpretação de conferências, interpretação comunitária, interpretação em tribunais ${ }^{2}$, interpretação na mídia, interpretação de acompanhamento ou ligação, interpretação médica, entre outras. A terminologia ainda não está consagrada em português, e é bastante comum os intérpretes se referirem a "escort interpreting" em inglês em vez de utilizarem "interpretação de acompanhamento". Não cabe aqui uma explicação sobre cada uma delas, mas deve-se levar em

2 A interpretação realizada em tribunais durante julgamento no Brasil é, por força da legislação, uma atribuição do tradutor público (juramentado). Tal fato corrobora a confusão existente entre tradutor e intérprete. 
conta que as referências feitas à interpretação no corpo deste artigo pressupõem basicamente a interpretação simultânea realizada em conferências ou congressos envolvendo participantes que falem línguas diferentes.

\section{Breve histórico da Interpretação}

A mais antiga referência a um intérprete parece ser um hieróglifo egípcio do terceiro milênio antes de Cristo. Há registros de intérpretes na antiga Grécia e no Império Romano. Na Bíblia, o Apóstolo Paulo faz a se-

guinte admoestação em sua Epístola aos Coríntios: "E se alguém falar em lingua desconhecida, faça-se isso por dois, ou quando muito três, e por sua vez, e haja intérprete" (I Coríntios 14:28). A atuação de intérpretes também está documentada na Idade Média, seja nas Cruzadas ou em encontros diplomáticos. No Novo Mundo, sabe-se que Colombo trouxe intérpretes em sua expedição, ainda que das línguas erradas: hebraico, caldeu e árabe. Mais conhecido e mais bem documentado é o caso de Doña Marina, famosa intérprete de Cortez em sua conquista do México (cf.: Hogg 1997).

Mas a interpretação de conferências mais próxima do que conhecemos atualmente teve início com a Primeira Guerra Mundial. Anteriormente, as negociações internacionais eram realizadas basicamente em francês, uma vez que essa era a língua comum aos diplomatas da época. Foi o que aconteceu, por exemplo, no famoso Congresso de Viena, realizado em 18141815. Com a entrada dos Estados Unidos na Grande Guerra, torna-se necessária a interpretação entre inglês e francês, uma vez que alguns dos representantes americanos, como também os da Inglaterra, não falavam francês com a fluência necessária para as negociações. Considera-se que o primeiro dos intérpretes modernos foi Paul Mantoux. Nascido e educado na França, era professor do University College, de Londres. Foi o principal intérprete das conferências realizadas na França imediatamente após a Primeira Guerra, que negociaram o Tratado de Versalhes.

No período de aproximadamente duas décadas entre as duas Guerras Mundiais, ganha ímpeto a interpretação consecutiva entre o inglês e o francês, as duas línguas utilizadas na Liga das Nações, sediada em Genebra, na Suíça. As coisas começam a complicar-se com a criação da Organização Internacional do Trabalho, uma vez que alguns representantes sindicais não falavam francês nem inglês e tinham de expressar-se em sua pró- 
pria língua. Utiliza-se aí uma combinação de interpretação consecutiva e "interpretação cochichada" ou chuchotage, como é conhecida nos meios profissionais, e um sistema primitivo de simultânea, que não teve grande sucesso. Pouco antes da eclosão da Segunda Guerra Mundial surge o equipamento, ainda que embrionário, que viria a possibilitar a interpretação simultânea como conhecida hoje em dia, produzido pela IBM. Com o início da Guerra e o fim da Liga das Nações, a idéia foi, inicialmente, abandonada (cf.: Herbert 1978; Gaiba 1998).

Ao final da Segunda Guerra, com a o advento do Julgamento de Nuremberg dos criminosos de guerra alemães, surge o problema de realizar um julgamento com quatro línguas principais: inglês, francês, russo e alemão. A consecutiva seria impensável, pois alongaria imensamente a duração das sessões do Tribunal, além de dificultar a mecânica de atuação de testemunhas, promotores, advogados, juízes e réus, falantes de diferentes idiomas. Quem recebeu a incumbência de encontrar a solução para o problema foi o Coronel Leon Dostert, intérprete do General Eisenhower. A IBM empresta o equipamento gratuitamente, tendo em vista a grande propaganda que seria o seu uso em tal ocasião. Dostert convoca jovens intérpretes consecutivos e outras pessoas sem experiência em interpretação, mas com excelente competência lingüística e, após alguns meses de experimentação e treinamento intensos, surge o embrião do que viria a ser a interpretação simultânea como a conhecemos hoje em dia (cf.: AIIC 1996; Gaiba 1998).

Segundo o vídeo comemorativo dos cinqüenta anos da profissão de intérprete produzido pela Associação Internacional de Intérpretes de Conferência (AIIC 1996), Dostert acreditava que era possível ouvir uma mensagem e expressá-la ao mesmo tempo, o que não era aceito pelos intérpretes consecutivos mais experientes que tinham atuado na Liga das Nações. Foi também Dostert quem insistiu na importância de os intérpretes serem colocados de maneira a ver o que acontecia no recinto para poderem ter a compreensão global do que se passava. Esse é um princípio básico do processo da interpretação simultânea, em que os intérpretes continuam a insistir hoje em dia, uma vez que dependem das expressões faciais e outros movimentos corporais tanto quanto das próprias palavras sendo proferidas, para terem uma compreensão global do sentido da mensagem. Os intérpretes em Nuremberg foram colocados no fundo do salão, perto dos réus, em "cabines" abertas de vidro, semelhantes a um guichê de agência 
bancária, que logo começam a ser chamadas de "aquários". Em cada uma delas, atuavam três intérpretes com a mesma língua de chegada e com três diferentes línguas de partida. Por exemplo, na chamada "cabine de inglês", atuavam três intérpretes que tivessem o inglês como língua A (ou língua materna), sendo que um intérprete trabalhava do francês para o inglês, outro do russo para o inglês e outro do alemão para o inglês. A mesma estrutura era encontrada na cabine de francês, de russo e de alemão. Assim, as equipes atuavam com doze intérpretes ao mesmo tempo, divididos em quatro cabines, com três intérpretes em cada uma, agrupados segundo sua língua materna, que era uma das quatro línguas de trabalho do Julgamento. Havia três equipes de doze membros, atuando alternadamente (cf.: AIIC 1996; Gaiba 1998). Esse sistema de trabalho adotado em Nuremberg era diferente do que se utiliza atualmente, em que os intérpretes atuam em duplas nas cabines, ambos com a mesma língua de partida e de chegada, aumentando-se o número de cabines (e de duplas de intérpretes) de acordo com as necessidades lingüísticas do evento.

Antes mesmo do fim do Julgamento de Nuremberg, é criada a Organização das Nações Unidas (ONU), para a qual são deslocados alguns intérpretes que atuavam em Nuremberg. É interessante notar que a Conferência de São Francisco, nos Estados Unidos, onde seria organizada a ONU, não previa a atuação de intérpretes. Segundo Herbert (1978:7), Stettinius, Secretário de Estado americano e anfitrião do evento, faz seu discurso de abertura em inglês e, para a sua surpresa, o Ministro das Relações Exteriores da França, George Bidault, que havia providenciado uma equipe de intérpretes da delegação francesa, faz um sinal para que iniciem a interpretação consecutiva para o francês, surpreendendo a todos. Fica claro, imediatamente, que a ONU não funcionaria sem intérpretes e que o inglês não seria a única língua da organização. Segundo o vídeo mencionado acima (AIIC 1996), ao inglês, somam-se o francês, o espanhol, o russo e o chinês como línguas de trabalho da ONU. Na década de 70, acrescenta-se o árabe e são essas, até hoje, as seis línguas oficiais da Organização. Aos poucos, a interpretação simultânea vai vencendo os preconceitos iniciais, ganhando confiança e prestígio, e vai substituindo a consecutiva nos diversos setores que compõem a família de organizações da ONU.

Na década de 50, é criada a CECA - Comunidade Européia de Carvão e Aço - que foi o embrião do Mercado Comum Europeu, hoje União Européia. Segundo um de seus fundadores e seu primeiro presidente, Jean Monnet, logo em seu início, reconhece-se a necessidade de um serviço de 
interpretação e é chamada a fazer parte dessa organização inicial uma jovem intérprete, Danica Seleskovitch, que deixaria profunda impressão nos serviços de interpretação da atual União Européia e viria a transformar o treinamento e a formação de intérpretes (cf Monnet 1975:iv). Ao contrário da ONU, na qual se estabeleceram seis línguas de trabalho fixas, a União Européia considera como línguas oficiais a de todos os países-membros, chegando hoje a 11 idiomas, com provável aumento à medida que outros países venham a ser aceitos como membros da União.

\section{A formação de intérpretes ontem e hoje}

Os primeiros intérpretes atuantes em Nuremberg, na ONU e na CECA foram formados na prática. Nos meios profissionais, diz-se que esses intérpretes foram "formados" pelo método "sink or swim", expressão em inglês que significa literalmente "afogue-se ou nade", e que se refere ao fato de que os intérpretes simultâneos eram colocados na cabine para interpretar sem que recebessem previamente qualquer treinamento formal.

A primeira escola especificamente criada para a formação desses profissionais foi a da Universidade de Genebra, na Suíça, em 1941, que a partir de 1972 passa a se dedicar também à formação de tradutores. (Université de Genève, 2000) . Em finais da mesma década de 40, é fundada por Dostert a Divisão de Interpretação e Tradução da Universidade de Georgetown, nos Estados Unidos, (Gaiba 1998) escola essa que acaba de ser extinta. Mas é a chegada de Danica Seleskovitch, à escola de intérpretes da Sorbonne, em 1956, que viria a alterar significativamente os métodos de formação de intérpretes. Seleskovitch viria a tornar-se um dos maiores nomes no ensino da interpretação e uma das mais conhecidas pesquisadoras da área. A AIIC (Associação Internacional de Intérpretes de Conferência) homenageou-a, dando seu nome ao prêmio internacional concedido a cada dois anos a um intérprete que preste serviços relevantes à profissão. Pöchhacker (1992:212), ao analisar o papel da teoria na interpretação simultânea, é claro: "De fato, Mme Seleskovitch merece total reconhecimento por ter feito oposição às estreitas concepções lingüísticas a respeito da língua, que ainda prevaleciam no início dos anos 70". Ainda a seu respeito, Christopher Thiery, intérprete-chefe do Ministério das Relações Estrangeiras da França e ex-presidente da AIIC, declara em um congresso realizado na Sorbonne: 
(...) eu gostaria de propor uma homenagem profissional a respeito da vida de Danica [Seleskovitch] e de tudo que ela fez. (...) Creio ser importante dizer três coisas [sic]. A primeira é que Danica não era nada além de intérprete, uma intérprete notável, como podem pressupor. Era também alguém que queria ver as coisas melhorarem. Ela quis imprimir sua marca à organização de uma profissão. (...) Em segundo lugar, Danica compreendeu que a interpretação era um meio de fazer outra coisa que enriqueceria seu trabalho de intérprete e a faria desabrochar plenamente. Foi certamente graças ao Professor Gravier que Danica veio a desenvolver sua tese, o que lhe abriu as oportunidades. Mas é evidentemente graças a Danica e a tudo o que ela suscitou a seguir - a princípio com o seu trabalho de pesquisa e depois com o trabalho que veio a se desenvolver a seu redor - que nós, profissionais, nos sentimos atualmente à vontade nos meios acadêmicos. (...) (Lederer e Israël 1990:300-301).

Antes do início de seu trabalho como professora de interpretação e pesquisadora na Sorbonne, o treinamento de intérpretes estava associado ao ensino de línguas estrangeiras. [Seleskovitch 1975:3] É Seleskovitch quem começa a refletir sobre o processo, vindo a desenvolver toda uma linha teórica sobre o assunto, a chamada "Teoria Interpretativa da Tradução" ou "Théorie du Sens" (Teoria do Sentido), conhecida em todo o mundo pelo seu nome original em francês. A inexistência de livros ou artigos traduzidos para português ocasiona a falta de uma terminologia consagrada em língua portuguesa. Essa teoria será discutida mais à frente neste trabalho.

A maior parte das escolas de formação de intérpretes encontra-se na Europa. Além da ETI (Universidade de Genebra) e da ESIT, (Sorbonne Nouvelle-Paris III), as mais tradicionais são o ISIT (Instituto Católico de Paris), a Universidade de Westminster, em Londres, anteriormente denominada Polytechnic of Central London e as faculdades que fazem parte da Universidade de Heidelberg, na Alemanha e da Universidade de Viena, na Áustria. Existem ainda diversos outros programas na Espanha, em Portugal, na Bélgica, na Itália e nos países do leste europeu. Nos Estados Unidos, com o fim das atividades da escola de formação de intérpretes da Universidade de Georgetown, o único programa pleno, cujo treinamento envolve diversos idiomais, restante é o do Monterey Institute of International Studies, na Califórnia, embora existam programas menores em diversas outras universidades. No Canadá, existe um programa pleno na Universidade de Ottawa. É interessante mencionar que praticamente todos os programas mencionados neste parágrafo não estão associados a cursos de Letras, como ocorre freqüentemente no Brasil, mas constituem faculdades dedicadas especificamente à formação de tradutores e intérpre- 
tes, inseridas na estrutura das respectivas universidades em pé de igualdade com as demais que integram o sistema universitário.

No Brasil, os pioneiros no desenvolvimento de um programa dedicado à formação de intérpretes foram a PUC do Rio de Janeiro e a Associação Alumni, em São Paulo. Posteriormente, foram criados programas que combinam a formação de tradutores e intérpretes ao mesmo tempo, como o da Faculdade Ibero-Americana, atualmente Unibero. E em 1999, foi criado o Curso de Formação de Intérpretes de Conferência de Língua Inglesa da PUC São Paulo.

\section{Teorização: A Teoria Interpretativa}

Há diversas teorias existentes relacionadas à tradução e, em menor número, à interpretação. Dentre elas, destaca-se a chamada théorie du sens, em francês, ou a Teoria Interpretativa da Tradução, desenvolvida por Danica Seleskovitch e sua equipe na ESIT, já mencionada acima. Desenvolvida a partir da experiência de décadas de Danica Seleskovitch como intérprete de conferências e detendo-se, a princípio, na interpretação de conferências, a Teoria Interpretativa da Tradução veio posteriormente a ser aplicada à tradução escrita per se, posição essa firmada definitivamente por Marianne Lederer (1994) em sua obra La Traduction Aujourd'bui: le modèle interprétatif. Tal aplicação consagra definitivamente a idéia de que os fundamentos teóricos são, de fato, os mesmos tanto no processo da tradução como no da interpretação.

Seleskovitch (1980:403) apresenta em alguns poucos parágrafos uma introdução aos princípios teóricos da Teoria Interpretativa da Tradução. Diz ela:

Se ao ler um jornal ou ouvir um discurso numa determinada língua, uma pessoa pensar que basta unicamente o conhecimento da língua em questão para compreender a mensagem, estará implicitamente acreditando na hipótese levantada por algumas teorias lingüísticas da tradução. Desde Saussure, os estudos da lingüística sincrônica tentam imprimir-lhe um cunho mais científico ao dissociar o estudo das línguas e de seu funcionamento do estudo de seu uso, propriamente dito, na dicotomia "língua X fala" da teoria saussuriana. No entanto, paralelamente ao aprofundamento dos estudos a respeito dos mecanismos e do funcionamento da linguagem em nível de língua, vimos surgir nas últimas três décadas a Psicolingüística, a Sociolingüística, 
as Teorias da Comunicação, as pesquisas empíricas dos Atos de Fala e de Análise do Discurso, além da própria LingüísticaTextual, que estuda as estruturas pragmáticas da língua. Todas essas áreas de estudo vão muito além do escopo da língua estabelecido pela lingüística pós-saussuriana, sem que, porém, deixem de possuir caráter científico.

Por outro lado, estruturalistas como G. Mounin ou R. Jakobson que viram a tradução humana exclusivamente sob o ângulo do funcionamento da língua, e um gerativista como N. Chomsky, que trabalhou indiretamente a favor da tradução mecânica, não perceberam que para estudar a tradução, deve-se abandonar o domínio dos sistemas de signos articulados, o domínio da competência lingüística neutra de um "native speaker" [em inglês no original francês], a fim de penetrar no domínio do ato de comunicação que é, por sua vez, a realização da língua e a expressão de um pensamento individual, o domínio das mensagens transmitidas pela fala e que são, ao mesmo tempo, compostas da língua e de conteúdos cognitivos ligados aos signos lingüísticos apenas de maneira transitória. O estudo da tradução exige que se levem em consideração não apenas a competência lingüística do indivíduo que compreende e fala, mas também sua bagagem cognitiva e suas capacidades lógicas. (...) Compreender um texto ou discurso não consiste apenas em identificar os conteúdos semânticos permanentes dos signos lingüísticos e a eles atribuir a significação que se depreende de sua combinação sintática em frases, mas também discernir os demais elementos cognitivos não-lingüísticos que, em uma dada situação, estão ligados ao enunciado.

Quais são, então os principais postulados teóricos da Teoria Interpretativa da Tradução? Em Seleskovitch (1978:9), a autora apresenta os três estágios que formam o arcabouço básico da teoria:

“1. Percepção auditiva de um enunciado lingüístico que é portador de significado. Apreensão da língua e compreensão da mensagem por meio de um processo de análise e exegese;

2. Abandono imediato e intencional das palavras e retenção da representação mental da mensagem (conceitos, idéias, etc.);

3. Produção de um novo enunciado na língua-alvo, que deve atender a dois requisitos: deve expressar a mensagem original completa e deve ser voltado para o destinatário."

Analisemos os três estágios mencionados acima. Nota-se aqui a origem da teoria, que deriva da forma oral de tradução, quando a autora menciona "percepção auditiva". A mesma teoria aplica-se à tradução escrita, como postulado por Lederer (1994) e mencionado mais adiante neste 
trabalho, pois a percepção do enunciado lingüístico pode ser feita tanto pela audição como pela leitura. Ainda no primeiro estágio, uma vez apreendida a mensagem por meio de sua forma lingüística, ela será analisada e compreendida para que se chegue ao sentido, por meio de uma fusão do significado lingüístico das palavras e frases com os "complementos cognitivos".

Segundo Lederer (1990:56-57), há três tipos básicos de "complementos cognitivos": contexto verbal, contexto situacional e contexto cognitivo. A respeito do primeiro deles, diz ela: "A fala é enunciada por meio de um fluxo contínuo de palavras, cada palavra contribuindo para o significado das palavras a seu redor e tornando-se mais específica pelas demais palavras que a acompanham. A interação significativa das palavras presentes da memória de trabalho é o primeiro nível de complementos cognitivos; ela acaba com a polissemia das palavras." O contexto situacional, explica a mesma autora aplicando o conceito à interpretação de conferência, tem a ver com o fato de que "os intérpretes fazem parte do evento no qual estão interpretando. Eles não somente vêem o participante, mas sabem quem são e qual a sua função ao falar. (...) A consciência do contexto situacional é mais um complemento cognitivo que faz com que se compreenda significados relevantes, eliminando a polissemia." Aplicando o mesmo conceito à tradução escrita, Lederer (1994:41) diz: "O tradutor identifica a realidade designada, a época em que o texto foi escrito, o autor, o público original (...) A bagagem cognitiva do tradutor permite-lhe reencontrar e transmitir as idéias e as emoções que o texto designa, mais do que aqueles que ele exprime." Por último, o contexto cognitivo é definido como: "um saber latente, desverbalizado, que intervém na compreensão das seqüências verbais sucessivas" (Lederer, 1994: 41). Em outras palavras, tanto no processo escrito como no oral, o profissional da tradução "faz uso de sua memória das coisas ditas anteriormente a fim de compreender as sentenças sendo enunciadas" (Lederer 1990: 57) Complementando a noção, a autora explica que ele "é cognitivo, uma vez que não mais tem uma forma verbal e contextual, uma vez que deriva de coisas já ditas” (Lederer,1990: 57).

Um conceito relacionado ao dos complementos cognitivos mencionados acima é o de "bagagem cognitiva" (Lederer 1990: 58; Lederer 1994: 36). Em outras palavras, a bagagem cognitiva é o "conhecimento de mun-

do que existe independentemente dos atos da fala. É o todo daquilo que conhecemos, quer seja por experiência, quer seja por meio do aprendizado. 
Partes relevantes desse conhecimento são mobilizadas pela cadeia enunciativa e contribuem para a compreensão [do que foi dito]" (Lederer 1990: 58). A bagagem cognitiva é, essencialmente, o que se chama em inglês de encyclopaedic (or world) knowledge (cf.: Lederer 1994: 38). Ela se associa aos demais elementos contextuais discutidos acima para, em associação ao significado lingüístico das palavras e frases, possibilitar que o tradutor ou intérprete cheguem ao sentido daquilo que está sendo dito.

É ainda importante mencionar mais um conceito ligado à teoria em discussão. Como não há relações previamente estabelecidas entre palavras ou expressões de duas línguas diferentes, tais relações são criadas tendo em vista como, onde, quando e por que razão alguma palavra ou expressão é utilizada, como já mencionado nos parágrafos anteriores. As exceções ficam, praticamente, por conta das palavras ditas "técnicas", dos nomes próprios (quer sejam de lugares, pessoas ou organizações) e de expressões numéricas. Esse processo recebe o nome de "transcodificação" (do francês, transcodage) (cf.: Lederer,1994: 46-48; Seleskovitch,1975: 11-31) e restringe-se basicamente a palavras que denotem quantidades, a nomes próprios e a palavras ou expressões de natureza técnica. Inclui exemplos como hepatitis (em inglês) sendo traduzido como "hepatite" em português; ou ainda London tornando-se "Londres" no texto em português. Nesses casos, não há necessidade de "interpretação" (significando aqui o ato de processar, interpretar o que foi dito no original usando-se a bagagem cognitiva do tradutor e os complementos cognitivos pertinentes) no processo tradutório, mas simplesmente utiliza-se a relação previamente estabelecida entre os dois idiomas e de domínio de ambas as comunidades lingüísticas.

O segundo estágio do processo é a chamada "desverbalização". O conceito é claramente explicado por Seleskovitch e Lederer (1995:24): "O processo da interpretação envolve a percepção de idéias, ou sentido, expressas no discurso. À medida que se percebe o sentido, as formas verbais utilizadas para transmiti-lo desaparecem, deixando apenas a consciência a partir da qual o intérprete pode espontaneamente expressar o sentido, sem estar preso à forma da língua de partida”.

O terceiro estágio envolve a chamada "reverbalização". É o momento em que o tradutor e o intérprete dão uma nova feição à mensagem já compreendida. Como claramente dito por Seleskovitch (1978:9), o novo enunciado deverá atender a dois critérios básicos: a mensagem original 
deve ser completa, provida de todos os detalhes e deve refletir as características da língua de chegada. Ao se traduzir do inglês para o português, por exemplo, o texto de chegada, quer seja ele escrito ou oral, deverá parecer ter sido produzido originalmente em português, sem traços que denotem sua origem no inglês.

Não se pode deixar de mencionar que existe uma outra linha teórica de pesquisa de interpretação, que denomina a si mesma de "comunidade das ciências naturais", e seus estudos são de natureza interdisciplinar com forte orientação, principalmente, da psicologia cognitiva e da neurologia e dão grande valor à chamada pesquisa empírica. Seus estudos, porém, são ainda de natureza bastante heterogênea. Diversos membros dessa comunidade científica

"escolheram aspectos bem específicos da interpretação e criaram estudos experimentais sobre eles. É comum entre os membros dessa comunidade a busca de uma teoria da interpretação que seja precisa e verificável, ainda que não necessariamente de simples compreensão, que tenha um alto grau de poder de explicação a fim de descrever objetivamente o ato de interpretação e, ao mesmo tempo, atender aos princípios rígidos da investigação científica." (Moser-Mercer 1994).

É ainda a mesma autora, ela própria uma das vozes mais influentes da chamada "comunidade das ciências naturais", quem afirma o seguinte a respeito da chamada "comunidade das ciências humanas", referindo-se ao trabalho de teorização e pesquisa desenvolvido pelo grupo encabeçado por Seleskovitch e Lederer:

A consistência geral da teoria (...), sua abrangência e simplicidade, seu valor explanatório intuitivo e conseqüente apelo pedagógico somaram-se para dar-lhe ampla aceitação. Assim, de várias maneiras, essa teoria atende a muitas das exigências inerentes a uma teoria em geral. (idem)

Há ainda inúmeros estudos teóricos relativamente recentes, que se ocupam basicamente da tradução em sua forma escrita, tanto no Brasil como em âmbito internacional. Podem-se mencionar no Brasil os trabalhos de Arrojo (1986) e Aubert (1994) e, em âmbito internacional, os de Baker (1992) e de Snell-Hornby (1995). A semelhança entre esses estudos e a teoria interpretativa da interpretação não pode ser de toda descartada, pois todos concordam basicamente que o processo tradutório não pode se 
deter apenas no nível lingüístico, devendo levar em conta o cultural e o situacional. Não cabe, aqui, entretanto, uma análise de todos esses estudos. Uma abordagem detalhada de várias posições teóricas pode ser vista em Pöchhacker (1992) e em Shlesinger (1995). Ambos os autores sugerem como estabelecer fundamentos teóricos que se apliquem tanto à tradução escrita como à oral (interpretação).

\section{Semelhanças básicas entre a tradução (escrita) e a interpretação (oral)}

O propósito principal tanto da tradução quanto da interpretação é fazer com que uma mensagem expressa em determinado idioma seja transposta para outro, a fim de ser compreendida por uma comunidade que não fale o idioma em que essa mensagem foi originalmente concebida. Arrojo (1986:80) cita a etimologia da palavra "tradução" e explica sua posição: "de acordo com a etimologia, tradução (do latim traductione) significa 'ato de conduzir além, de transferir' (...) Como tentamos demonstrar, traduzir, mais do que transferir, é transformar: 'transformar uma língua em outra, e um texto em outro' (Jacques Derrida).” Pode-se dizer que o tradutor e o intérprete são profissionais que permitem que uma mensagem cruze a chamada "barreira lingüística" entre duas comunidades, sendo comum usar a metáfora "ponte" para designar esses profissionais. Tal imagem é mesmo utilizada no título de conhecida obra escrita pelo tradutor e ensaísta brasileiro recentemente falecido, José Paulo Paes, que a intitulou "Tradução: A Ponte Necessária - Aspectos e Problemas da Arte de Traduzir” (Paes 1990).

Alguns autores já apontaram a semelhança essencial entre os processos de tradução e interpretação. Harris (1981:154) afirma: "É melhor admitirmos logo de início que a tradução e a interpretação têm muito em comum. Em resumo, são apenas dois modos daquilo que é, essencialmente, uma única operação: um processo por meio do qual um enunciado falado ou escrito acontece em um idioma, que tem a intenção e a expectativa de transmitir o mesmo significado previamente existente no enunciado de outro idioma." Lederer (1994:11) também fala a respeito da semelhança entre a tradução e a interpretação: "A teoria interpretativa (...) estabeleceu que o processo consistia em compreender o texto original, desverbalizar sua forma lingüística e expressar em outra língua as idéias compreendidas e os sentimentos experimentados. Essa constatação, feita 
inicialmente a respeito da tradução oral, ou interpretação de conferências, aplica-se também à tradução escrita."

Outra semelhança é que tanto na tradução quanto na interpretação, é preciso dominar plenamente os dois idiomas envolvidos no processo, embora ao tradutor baste o domínio de sua forma escrita e ao intérprete, a sua forma oral. Há excelentes tradutores de textos escritos que não são capazes de compreender a forma oral da língua da qual traduzem. Em outras palavras: compreendem perfeitamente um texto lido na língua estrangeira de trabalho, mas não são capazes de entender um texto semelhante se apresentado oralmente por seu autor, em forma de conferência ou palestra, por exemplo. Esse tipo de profissional também teria dificuldades para manter uma conversa no mesmo idioma do qual traduz muito bem um texto escrito. Caso o profissional tenha o conhecimento da língua-fonte na forma escrita para fins de leitura, nada impede um excelente desempenho como tradutor para sua língua materna, desde que tenha um bom domínio da forma escrita de seu próprio idioma. Paulo Rónai, o fundador da Associação Brasileira de Tradutores (ABRATES), afirma: "Muitas vezes nasceram traduções relativamente boas feitas de línguas que os tradutores não falavam. Muitas vezes esses têm da língua de partida apenas um estudo livresco, sem conhecerem o país onde ela é falada. (...) E no caso de obras gregas e latinas, o conhecimento da língua-fonte, por mais sólido que seja, é quase sempre apenas passivo." (Rónai 1981:27-28) O intérprete, por outro lado, recebe toda a mensagem original em forma oral e precisa ter total domínio da forma oral da língua de partida, percebendo sutilezas de pronúncia, nuances de entonação, sendo capaz de compreender diferentes variantes regionais do idioma estrangeiro. Necessita, obviamente, de total domínio das formas de expressão oral de seu próprio idioma, mesmo que não tenha um bom domínio da escrita em sua própria língua.

Outra semelhança ainda é que tanto a tradução quanto a interpretação devem ser realizadas por profissionais capazes de compreender e expressar idéias relacionadas às mais diferentes áreas de conhecimento humano, sem ser especialistas nessa área, como o são seus leitores ou ouvintes. Como diz Seleskovitch (1978:148): 
Raras são as atividades nos dias de hoje, estejam elas relacionadas à ciência ou tecnologia, finanças ou comércio, agricultura ou indústria, tribunais de arbitragem ou controle de gafanhotos, que não se estendam para além das fronteiras de um país e, conseqüentemente, envolvam mais de uma língua.

Portanto, a interpretação não é mais restrita, como já o foi, a negociações diplomáticas, e o intérprete pode vir a ser chamado para (...) atuar em qualquer área de atividade humana contemporânea.

Tal constatação, obviamente, aplica-se também à tradução, pois além de conferências e palestras, também existirão sempre textos escritos a respeito dos mesmos assuntos. No entanto, não é possível que os profissionais que realizam a atividade tradutória dominem a área médica, por exemplo, como se fossem médicos. No entanto, os congressos médicos oferecem regularmente interpretação simultânea realizada por intérpretes e não por médicos. O mesmo se aplica a outras áreas de conhecimento como engenharia, economia, marketing, etc. No que concerne à forma escrita da língua, as traduções de documentos e contratos, por exemplo, são realizadas no Brasil por tradutores juramentados que não são, necessariamente, advogados. É por isso que as pessoas envolvidas profissionalmente nas atividades de tradução e de interpretação devem manter-se atualizadas no desenvolvimento constante das áreas de conhecimento com as quais trabalhem e consultar especialistas da área, quando necessário. Via de regra, o tradutor ou o intérprete escreve ou fala a respeito de um assunto que não domina plenamente, tendo como audiência especialistas desse assunto, que o conhecem muito mais a fundo.

É interessante mencionar ainda o papel desempenhado pela memória nos dois processos, "mais especificamente o papel dos processos de memória para fortalecer pressuposições contextuais ma fase de reformulação, tanto em interpretação quanto em tradução" (Alves e Pagura 2002:75). Tanto na tradução quanto na interpretação pode-se perceber que as pressuposições contextuais existentes formam a base dos processos inferenciais nos dois processos. "Tanto a interpretação quanto a tradução podem ser vistas como processos que fazem parte do espectro de processos inferenciais humanos e podem ser explicadas como parte de uma visão mais ampla da comunicação humana" (Alves e Pagura 2002, 76). 


\section{As diferenças entre os dois processos}

Presumindo-se que os fundamentos teóricos podem ser considerados os mesmos como já mencionado acima, conclui-se que as diferenças entres os processos de tradução e de interpretação são, basicamente, de operacionalização (cf.: Lederer 1994:1; Harris,1981:154). Tanto a fonte da mensagem como o resultado do processo se dão em formas distintas escrita e oral, respectivamente - resultando daí diferenças operacionais. Seleskovitch (1978:2) também trata do assunto: "Essas profissões gêmeas [tradução e interpretação] têm o mesmo objetivo, atuam com base nos mesmos princípios e são - ou podem ser - baseadas na mesma teoria. (...) A tradução converte um texto escrito em outro texto escrito, enquanto a interpretação converte uma mensagem oral em outra mensagem oral. Essa diferença é crucial."

Como já foi mencionado acima, o domínio dos idiomas de trabalho e do assunto por parte do profissional que realiza o ato tradutório deve ser excelente. $\mathrm{O}$ intérprete, no entanto, tem de ter pleno domínio das formas de expressão oral de ambos os idiomas. Não seria arriscado dizer ainda que o intérprete terá de ter maior domínio das línguas, do assunto, da culturafonte e da cultura-alvo do que o tradutor. Tal afirmação não será temerária quando se consideram as condições de trabalho em que ocorrem os dois processos. Na tradução, o processo pode ser interrompido para a consulta de dicionários, enciclopédias, sites da Internet e uma infinidade de obras de referência. Podem ainda ser consultados outros profissionais, quer sejam tradutores, quer especialistas da área de conhecimento com a qual estejam trabalhando. Além disso, o texto traduzido poderá ser revisado diversas vezes, até ser encontrada a melhor forma de expressão ou ainda se fazerem mudanças, se posteriormente, for descoberto um termo mais preciso para determinado conceito. Como dizem Padilla e Martin (1992:196): "O texto escrito é estático porque foi produzido no passado. O tradutor pode consultá-lo em seu próprio ritmo, a seu próprio tempo, utilizando os recursos que considerar necessários".

$\mathrm{Na}$ interpretação, por outro lado, todo o conhecimento necessário e o vocabulário específico terá de ter sido adquirido antes do ato tradutório em si. Durante o processo de interpretação simultânea, fechado em sua cabine e tendo que tomar decisões em questão de segundos, não há tempo para o intérprete realizar consultas de qualquer natureza. No máximo, 
poderá ter a ajuda do companheiro de cabine em alguma expressão recorrente no discurso que não lhe tenha vindo à mente a princípio. É claro que o intérprete absorve conhecimento do assunto no decorrer da própria palestra ou do evento que esteja interpretando, num processo que a Teoria Interpretativa da Tradução (cf.: Lederer,1990:56-57) rotula de "contexto situacional”, mas as bases sobre as quais tal conhecimento será construído têm de ser estabelecidas previamente, em sua preparação para o trabalho em questão. Sua bagagem cultural (cf.: Lederer,1990: 58; Lederer 1994: 36-38) tem de ser imensa, pois é impossível prever quais exemplos ou histórias serão utilizados por um palestrante para ilustrar um determinado assunto. Como afirmam Padilla e Martin (1992:197)

“[p]ara o intérprete, o processo de compreensão é muito mais complicado. Ele não tem tempo de usar dicionários ou consultar um especialista. A única maneira em que o intérprete pode afetar o processo de compreensão é tomando atitudes préviamente, antes que a mensagem seja realmente comunicada, por intermédio da preparação exaustiva, tanto lexical como conceitual, a respeito do assunto envolvido.

Outra diferença importante é o ritmo em que se dá o trabalho. Apesar de os clientes dos tradutores sempre necessitarem da tradução "com a máxima urgência”, o volume de tradução processado em determinado espaço de tempo será sempre muito menor em sua forma escrita do que na forma oral. Enquanto nas organizações internacionais, espera-se que os tradutores de tempo integral traduzam cerca de 50 linhas a cada duas horas, um discurso cujo texto transcrito tenha as mesmas 50 linhas será interpretado em cerca de oito minutos, conforme dados apresentados por Seleskovitch e Lederer (1995:v). Seleskovitch acrescenta ainda que a interpretação acontece numa velocidade "30 vezes maior" (1978:2) do que o processo de tradução. É óbvio que, nessas condições, não é possível qualquer tipo de revisão da mensagem expressa. Enquanto a tradução é revisada pelo tradutor e, freqüentemente, por um outro leitor, o resultado do trabalho do intérprete é final. Se o que for dito não conseguir transmitir a mensagem, dificilmente haverá tempo para que a mensagem seja re-expressa de maneira diferente. No entanto, os intérpretes experientes conseguem, na maioria das vezes, corrigir ou emendar algum sentido mal expresso com uma determinada palavra ou frase, ainda que só o façam normalmente duas ou três frases adiante. Isso exige, porém, bastante segurança por parte do intérprete no próprio processo de interpretação. Caso 
ele não se dê conta do eventual erro, não há a figura do revisor, que possa corrigir o problema antes que o produto de seu trabalho chegue ao público-alvo como, pelo menos teoricamente, acontece com a tradução escrita. (cf.: Padilla e Martin,1992:198-199) Uma vantagem do intérprete em relação ao tradutor a esse respeito, porém, é que o seu trabalho desaparece quando o evento termina, enquanto o trabalho do tradutor, impresso e publicado, permanecerá indefinidamente. Seleskovitch (1978:18) ilustra esse fato citando um provérbio latino - scripta manent, verba volant - para reiterar essa diferença: as palavras escritas permanecem para a posteridade, enquanto a palavra falada desaparece.

A tradução e a interpretação são normalmente realizadas por pessoas com características um tanto diferentes. $\mathrm{Na}$ tradução, o trabalho tem característica bastante individual, isolado. É realizado por alguém que trabalha inúmeras horas sozinho, diante de um computador, com seus dicionários e livros; só eventualmente troca idéias de seu trabalho com algum colega, seja pessoalmente, por telefone ou por e-mail, quando em caso de dúvidas ou busca de soluções melhores para determinado problema. A interpretação, por outro lado, é eminentemente um trabalho de equipe, quer seja em dupla ou em várias duplas, como acontece em eventos que envolvam diversas línguas ou que, apesar de envolverem apenas duas línguas, extendam-se por diversos dias.

O resultado do trabalho de interpretação é sentido imediatamente nas reações da platéia e, principalmente, nas perguntas ou no debate após uma conferência. Os bons intérpretes realmente se mostram nas perguntas e respostas. Quando essa parte da reunião flui sem problemas, fica patente que o trabalho do intérprete está sendo bem desempenhado. Essa observação foi corroborada por Lederer em comunicação pessoal com o autor deste trabalho em 2001 e em publicação, quando afirma: "A melhor maneira de julgar a qualidade da interpretação é ouvir o período de discussões em que as pessoas fazem perguntas umas às outras. Se isso estiver acontecendo em duas ou três línguas e as pessoas mostrarem-se satisfeitas com as respostas, pode-se afirmar que a comunicação foi estabelecida, que a interpretação teve êxito e que o processo envolvido foi representativo". $(1978: 324)$

Outra diferença fundamental entre a tradução e a interpretação está relacionada ao processo de análise e retenção de conteúdo. O texto de 
partida na interpretação, diferente do que acontece na tradução, não está à disposição indefinidamente. O intérprete (simultâneo) tem de ter a capacidade de concentrar-se no que está ouvindo a fim de processar a informação imediatamente e re-expressá-la na língua-alvo, sem se descuidar da próxima unidade de sentido sendo expressa pelo palestrante imediatamente a seguir. Como mencionado anteriormente neste trabalho, o processo da interpretação simultânea é tríplice - ouvir / processar / re-expressar (Seleskovitch:1978; Seleskovitch e Lederer:1995) e as três etapas acontecem ao mesmo tempo. $\mathrm{Na}$ interpretação consecutiva, as duas primeiras etapas ocorrem simultaneamente e a terceira (re-expressão) ocorrerá posteriormente, exigindo ainda mais capacidade de retenção da informação. (cf.: Seleskovitch:1975) A capacidade de analisar o conteúdo da mensagem, depreendendo os elementos de coesão que "amarram" a seqüência de pensamento do palestrante, é uma habilidade fundamental a ser utilizada no processo. Uma vez compreendida a mensagem, seu conteúdo terá de ser lembrado até o momento de ser expresso na língua de chegada, respeitando-se as características desse idioma e dessa cultura. Não é incomum, porém, que o sentido de um enunciado só se torne claro após diversas frases ou mesmos parágrafos, mas não é obviamente possível que o intérprete espere todo esse tempo para começar a falar. Nesses casos, o processo interpretativo exige uma "transposição lingüística ou transcodificação" (Lederer 1978:324) de maneira calculada, até que a compreensão da idéia permita que o intérprete se liberte das palavras e parta, uma vez mais, para a re-expressão da mensagem de forma mais distante da sintaxe e léxico da língua de partida e mais adequada à língua de chegada. A concentração tem de ser total, e por essa razão os intérpretes trabalham em duplas e se revezam a intervalos entre 20 e 30 minutos. Nada semelhante ocorre no processo de tradução escrita, pois o texto original está à disposição do tradutor para ser consultado tantas vezes quanto necessárias e pode ser lido inteiramente antes de se iniciar a tradução. A forma de expressão, por sua vez, poderá ser trabalhada até se chegar ao considerado ideal.

\section{Implicações para a formação de tradutores e de intérpretes}

Em sua obra clássica, Nida (1964:150) declara a respeito do domínio lingüístico por parte dos tradutores: 
O primeiro e mais óbvio dos requisitos de qualquer tradutor é que tenha conhecimento satisfatório de língua de partida. Não basta que ele seja capaz de compreender o sentido geral do texto, ou que tenha o hábito de consultar dicionários (o que terá de fazer de qualquer modo). Ele deverá entender não somente o conteúdo óbvio da mensagem, mas também as sutilezas de significado, o valor emotivo significativo das palavras e as características estilísticas que determinam o "sabor e sentimento" da mensagem (...)Ainda mais importante do que o conhecimento dos recursos da língua de partida é o controle completo da língua de chegada. (...) [N]ão há substituto para o domínio pleno da língua de chegada.

Embora Nida refira-se a tradutores, a mesma exigência obviamente aplica-se a intérpretes. Jones (1998:12) deixa isso bem claro:

Ao falarmos de compreesão, referimo-nos não à compreensão de palavras, mas de idéias, pois são as idéias que teremos de interpretar. Obviamente, não se podem compreender as idéias se não se compreenderem as palavras que o orador está utilizando para expressá-las, or caso não se esteja suficientemente familiarizado com a gramática e a sintaxe da língua do orador, para que seja possível acompanhar suas idéias.

Como já foi mencionado anteriormente neste trabalho, a ênfase no conhecimento lingüístico necessário ao processo de tradução está na língua escrita, ao passo que para a interpretação se faz necessário o domínio da língua oral. Esse domínio é condição prévia necessária e indispensável para a formação de tradutores e de intérpretes. Os programas de formação desses futuros profissionais não têm como seu objetivo o ensino de línguas. O domínio das línguas de trabalho antecede a formação de tradutores e intérpretes propriamente dita.

A partir dos princípios teóricos expostos acima, podem-se fazer algumas recomendações para a formação de tradutores e de intérpretes. Uma vez que o primeiro dos três estágios preconizados pela Teoria Interpretativa da Tradução está centrado na "apreensão da língua e compreensão da mensagem por meio de um processo de análise e exegese” (Seleskovitch 1978:9), o primeiro passo na formação de futuros tradutores e de futuros intérpretes consiste em "ensinar os alunos a perceberem e analisarem uma mensagem" (Seleskovitch e Lederer 1995:2). Em outras palavras, tanto o tradutor quanto o intérprete devem ser capazes de apreender o sentido de uma mensagem. Seleskovitch (1984:269) define o que é sentido (sens, em francês), princípio fundamental da Teoria Interpretativa da Tradução: 
"O sentido de uma frase é o que um autor quer deliberadamente exprimir; não é a razão pela qual ele fala, nem as causas ou conseqüências do que ele diz. O sentido não se confunde com os motivos nem com as intenções. $O$ tradutor que se faça passar por exegeta e o intérprete que se faça passar por hermeneuta estará indo além dos limites de sua função."

Num primeiro estágio de formação, tanto os futuros tradutores como intérpretes deverão ser expostos a exercícios que tenham o objetivo de lhes ensinar a perceber o sentido de uma mensagem. Esses exercícios estarão centrados na língua oral para intérpretes e na língua escrita para tradutores. Em outras palavras, os futuros tradutores deverão trabalhar a partir de textos escritos enquanto os futuros intérpretes farão exercícios a partir de gravações ou de trechos lidos pelo professor. Os exercícios de compreensão auditiva para intérpretes diferem daqueles utilizados comumente em cursos de ensino de língua estrangeira, chamados comumente em inglês de listening comprehension exercises. Seleskovitch e Lederer (1995:2) preconizam o seguinte: "O intérprete ouve [da seguinte maneira]: o intérprete concentra-se completamente no significado do que o orador quer dizer, captando todas as nuanças e sutilezas". A seguir, o aluno deverá ser capaz de reproduzir a mensagem, ainda que de forma resumida, transmitindo o sentido, a intenção do original. Exercícios semelhantes podem ser utilizados para tradutores, partindo-se de textos escritos, como já mencionado. A reprodução, neste estágio, pode ser feita oralmente, pois o objetivo ainda não é o de re-expressar a mensagem em sua forma final, mas sim o de treinar o aluno no processo de depreensão do sentido. Esses exercícios tem como objetivo precípuo levar o aluno a parafrasear o original, reproduzindo o seu conteúdo na mesma língua que leu o ouviu o texto original. Mais uma vez reitera-se: o objetivo aqui é a compreensão do sentido do original e não a re-expressão em outra língua.

Uma vez que o processo de depreensão do sentido tenha sido compreendido pelo aluno, o estágio seguinte concentra-se na re-expressão da mensagem. O segundo e o terceiro estágios do processo tendem a se fundir aqui, pois o "abandono imediato e intencional das palavras e retenção da representação mental da mensagem" só será demonstrado por intermédio da "produção de um novo enunciado na língua-alvo, que deve atender a dois requisitos: deve expressar a mensagem original completa e deve ser voltado para o destinatário" (Seleskovitch 1978:9). Embora, mais uma vez, os exercícios enfatizem a língua escrita ou oral conforme o caso, é 
importante que seja salientada sempre a importância da desverbalização, ou seja, da retenção e re-expressão das idéias e conceitos, e não de palavras da mensagem original, quer seja na forma escrita ou na oral. A esse respeito, sugerem Seleskovitch e Lederer: "A única maneira de combater a interferência [da língua de partida na língua de chegada] é insistir na completa dissociação das duas línguas em questão (...) Nos primeiros estágios do treinamento, um dos mandamentos deve ser o de que nada deva ser dito da mesma forma que o original (...)" (1995:26). Esses princípios básicos aplicam-se tanto à formação de tradutores quanto de intérpretes, pois são essencialmente os mesmos, variando apenas quanto à forma oral ou escrita.

Nesse momento inicial, a formação do tradutor e do intérprete concentra-se em princípios básicos e nada impede que esse estágio inicial seja realizado em conjunto. Outro componente que também se aplica a ambos é a introdução a princípios teóricos. A teoria pode ser ensinada como um componente separado ou ser apresentada em conjunto com os exercícios práticos iniciais delineados acima e a eles aplicada continuamente. "Esse é um estágio fundamental em seu treinamento, durante o qual adquirem a metodologia para dominar as técnicas (...), aprendem a dissociar a língua de partida da língua de chegada e a transmitir o sentido. Se entenderem esses objetivos desde o início, conseguirão concentrar seus esforços na direção certa (...)"(Seleskovitch e Lederer 1995:21).

A partir desse início, é necessário que a formação se dirija a componentes específicos inerentes ao processo de tradução e ao de interpretação. O futuro tradutor irá trabalhar os princípios delineados acima em exercícios específicos de tradução, com ênfase em aspectos inerentes à expressão em língua escrita como, por exemplo, a coesão textual. O futuro intérprete, por outro lado, deverá ser introduzido a princípios de oratória e de colocação da voz, além de dedicar muitas horas ao treino específico de interpretação consecutiva, que inclui a técnica de tomar notas, e finalmente o treino específico de interpretação simultânea, em que desenvolverá as técnicas necessárias ao trabalho na cabine. Mais uma vez, a ênfase será sempre no processo tríplice já mencionado acima, com destaque para a desverbalização da mensagem original e sua re-expressão de acordo com a língua de chegada.

Diferentes escolas adotam diferentes currículos. Christoph Renfer (1992:175) aponta "quatro modelos básicos de treinamento para tradutores e/ou intérpretes. 
A. Cursos de tradução e interpretação oferecidos em estágios consecutivos. (...) Os candidatos a intérpretes têm de ser aprovados no exame final de tradução e, a seguir, serem aprovados no teste de admissão ao programa de interpretação. (...);

B. Cursos para tradutores e para intérpretes funcionando paralelamente, com dois exames finais separados;

C. O 'modelo-Y' de treinamento de tradutores e intérpretes. Nesta abordagem, o currículo para tradutores e para intérpretes bifurca-se depois de um currículo comum básico para todos os alunos;

D. Treinamento de intérpretes em nível de pós-graduação (...) ou treinamento em-serviço intensivo em organizações internacionais."

O modelo A, por exemplo, é o adotado pela Universidade de Genebra, o modelo B pela Sorbonne Nouvelle, o modelo C pelo Monterrey Institute e o modelo D pela Universidade Westminster, em Londres, e pela União Européia. Não cabe no escopo do presente trabalho uma análise de cada um desses quatro modelos, o que é feito por Renfer. O que fica claro em todos os modelos apresentados é que, quer desde o primeiro momento de formação ou em um estágio posterior, a formação do tradutor e a do intérprete pressupõe o treinamento em técnicas e habilidades específicas inerentes às diferenças existentes entre a operacionalização dos dois processos. Nada impede, porém, que uma pessoa atue nas duas áreas, desde que tenha desenvolvido as técnicas e habilidades utilizadas em ambas.

\section{Conclusão}

A partir das três perguntas iniciais - Quais são as semelhanças entre os dois processos que poderiam ter gerado tal confusão? E quais são as diferenças que viriam a justificar uma separação entre as duas atividades? Que implicações essas possíveis semelhanças e diferenças teriam para o processo de formação de tradutores e de intérpretes? - podemos concluir o seguinte: há, de fato semelhanças entre os dois processos, conforme foi demonstrado neste trabalho e como concluíram os diversos autores citados. Há também diferenças fundamentais entre a operacionalização da tradução e da interpretação, que deixam claro tratarem-se de duas atividades distintas, ainda que semelhantes. Essas diferenças apontam para a necessi- 
dade de formação diferenciada para as duas atividades. Essa formação, no entanto, poderá aproveitar-se das semelhanças entre os dois processos e da base teórica comum para justificar programas que sigam o modelo " $\mathrm{A}$ " e "C", conforme descritos por Renfer (1992) e mencionados acima. Nada impede, porém, que uma instituição opte pelo modelo "B" de Renfer (1992) e se dedique à formação destinada exclusivamente à tradução ou interpretação, em programas separados. Tudo dependerá, obviamente, dos interesses e circunstâncias individuais das instituições e dos interessados na formação. Esse último caso é, por exemplo, a situação dos programas existentes na Pontifícia Universidade Católica de São Paulo, em que os programas de formação de tradutores e de intérpretes são separados.

\section{E-mail: reynaldop@uol.com.br \\ Recebido em junho de 2002}

\section{REFERÊnCIAS Bibliográficas}

AIIC. (s/d). Advice to students wishing to become conference interpreters. Genebra: AIIC.

AIIC. 1996. The interpreters: a historical perspective. (Vídeo). Genebra: AIIC.

Alves, F. e R. Pagura. 2002. The Interfaces between Written Translation and Simultaneous Interpretation: Instances of Cognitive Management with a Special Focus on the Memory Issue.In: Proceedings of the XVI FIT World Congress. Vancouver, Canadá.

Arrojo, R.1986. Oficina de tradução: a teoria na prática. São Paulo: Ática.

AuberT, F. H. 1994. As (in)fidelidades da tradução: servidões e autonomia do tradutor. Campinas: UNICAMP.

BAKER, M.. 1992. In other words: a coursebook on translation. Londres: Routledge.

CHILD, J. 1992. Introduction to Spanish translation. Lanham, MD: University Press of America.

Commission of the European Communities. (s/d). Short training courses in conference interpreting. [Bruxelas]

GaIBA, F. 1998. The Origins of Simultaneous Interpretation: The Nuremberg Trial. Ottawa, Canada: University of Ottawa Press.

Harris, B. 1981. Prolegomenon to a study of the differences between teaching translation and teaching interpretation. In: J. DelisLe. (org). 
L'enseigmenent de l'interpretation et de la traduction simultanée. Ottawa: University of Ottawa Press.

Herbert, J. 1978. How conference interpretation grew. In : D. Gerver e H. SinAIKo (orgs.), Language, interpretation and communication. Nova York: Plenum Press.

Hogg, D. (org). 1997. AIIC expo, slide show. Website da Association ternationale des Interprètes de Conférence, (aiic.net)

Jones, R. 1998. Conference interpreting explained. Manchester: St, Jerome.

Lederer, M. 1978. Simultaneous interpretation: units of meaning and other features. In: D. Gerver e H. SinAIKo (orgs.) Language interpretation and communication. Nova York: Plenumm Press.

Lederer, M. e F. IsRAëL (org.). 1990. La liberté en traduction: Actes du colloque international tenu à l'E.S.I.T. les 7, 8 et 9 juin 1990. Paris: Didier Érudition.

Lederer, M. 1990. The role of cognitive complements in interpreting em D. Bowen e M. Bowen. Interpreting-yesterday, today and tomorrow. American Translators Association Scholarly Monograph Series, vol. 4, Binghamton, N.Y.: SUNY.

Lederer, M. 1994. La Traduction Aujourd'bui-Le Modèle Interprétatif. Paris: Hachette.

MikKelson, H. 2000. Interpreting is interpreting-Or is it? [Artigo publicado no site acebo.com]

Monnet, J. 1975. In: D. Seleskovitch, Langage, langues et memoire: étude de la prise de notes en interprétation consécutive. Paris: Minard.

Moser-Mercer, B. 1994. Paradigms gained or the art of productive disagreement. In: S. LAMBert e B. Moser-Mercer (orgs.), Bridging The Gap. Empirical Research In Simultaneous Interpretation. Amsterdã: John Benjamins.

NidA, E. (1964) Toward a science of translating. Leiden: E.J.Brill.

Padilla, P. e Martin, A. 1992. Similarities between interpreting and translation: implications for teaching. In: C. Dollerup e A. LINDEGAARD (orgs.) Teaching translation and interpreting: training, talent and experience. Amsterdã: John Benjamins.

Paes, J. 1990. Tradução: A Ponte Necessária-Aspectos e Problemas da Arte de Traduzir. São Paulo: Ática.

PÖCHHACKer, F. 1992. The role of theory in simultaneous interpreting. In: C. Dollerup e A. LindegaARD (orgs.), Teaching translation and interpreting: training, talent and experience. Amsterdã: John Benjamins. 
Renfer, C. 1992. Translator and interpreter training: a case for a two-tier system. In: C. Dollerup e A. LindegaArd (orgs.) Teaching translation and interpreting: training, talent and experience. Amsterdã: John Benjamins.

RónAI, P. 1981. A tradução vivida. 2. ed. rev. e aum. Rio de Janeiro: Nova Fronteira.

Seleskovitch, D. 1975. Langage, langues et memoire: etude de la prise de notes en interprétation consécutive. Paris: Minard.

1978. Interpreting for international conferences. Tradução de L'interprete dans les conferences internationales: problèmes de langage et de communication. Washington: DC, Pen and Booth.

.1980. Pour une théorie de la traduction inspirée de sa pratique. Meta, v. 25, n. 4.pp. 401-408. Montreal: Presses de l'Université de Montréal.

Seleskovitch, D. e M. Lederer. 1984. Interpréter pour traduire. Paris: Didier Édurition.

. 1995. A systematic approach to teaching of interpretation. Tradução de Pédagogie raisonnée de l'interprétation. $\mathrm{n} / \mathrm{c}$ : The Registry of Interpreters for the Deaf.

Shlesinger, M. 1995. Stranger in paradigm: what lies ahead for simultaneous research? Target, v. 7, n. 2, pp. 7-28. Amsterdã: John Benjamins.

SNell-Hornby, M. 1995. Translation studies: an integrated approach. Amsterdã: John Benjamins.

Université de Genève. 2000. École de traduction et d'interprétation: Guide de l'étudiant. 